\title{
Accusation, Mitigation and Resisting Guilt in Talk
}

\author{
Richard Fitzgerald*,1 and Helena Austin ${ }^{2}$
}

\author{
${ }^{I}$ School of English Media Studies and Art History, University of Queensland, St Lucia., Brisbane, QLD 4072, Australia; \\ ${ }^{2}$ School of Educ. \& Professional Studies (Gold Coast), Griffith University, Gold Coast Campus, QLD 4222, Australia
}

\begin{abstract}
The notion of 'guilt' has been subject of examination through the methods of Membership Categorisation Analysis as a part of the work of formal institutions such as courts, police, and schools where the consequences of decisions made may have direct effects on the person being judged. However whilst this research has provided access to the process of 'negotiating' guilt in these highly ritualized and formal contexts the ascription, negotiation and resistance of guilt is not restricted to these institutions. Rather deciding someone's 'guilt' or resisting such a categorisation can be seen as part of the routine everyday work of social life. In this paper we use the method of Membership Categorisation Analysis to examine two instances where "guilt" is a matter of local negotiation between parties and where the consequences are purely a matter for the participants at hand: a narrative therapy counseling session and a conversation between friends. In the first site the negotiation is around a participant 'feeling guilty' whilst in the second, guilt is attributed to absent third party. Through our analysis we highlight that the interactional work of ascribing and resisting 'guilt' is both a routine feature of social interaction and that this routine feature is organised through members' methodical use of descriptions and accounts embedded in a common sense relationship between individual and categorial actions.
\end{abstract}

\section{INTRODUCTION}

In institutional contexts such as courtrooms (Drew, 1992; Drew \& Atkinson, 1979; Lynch \& Bogen, 2005; Pollner, 1987), police interrogations (Watson, 1997) and educational psychologists (Hester, 2008), the work of ascribing 'guilt' has been shown to be overwhelmingly organised through individual accounts of action placed alongside categorial attributes, such that individual action is treated as documenting (deviant) categorial membership. Within institutional settings the decision of someone's guilt is a product of reasoning practices between members institutionally charged with making a decision upon a person's actions, and invoking further actions in respect to that decision. However, whilst reasoning practices around deciding someone's guilt are seen as the business of some institutional talk, ascribing, reasoning and negotiating guilt, as we discuss below, are not confined to formal institutional talk. Rather the work of accusations, assumptions, imputations and defense are a routine part of social interaction. That is to say, deciding if someone is 'guilty' of something is overwhelmingly a matter of local negotiation, drawing upon commonsense knowledge in order to decide, through practical analysis of someone's actions, that the guilt can be ascribed to them. In the study of social interaction and human communication the power to define or decide someone's 'guilt', to cast that person as a member of a category, which if successful, can then involve subsequent consequential actions such as incarceration, punishment, separation, castigation etc. Whilst previous research, mentioned above, has examined the formal procedures of deciding guilt our focus is in the mundane ordinary informal interactional methods of negotiating 'guilt', of the

*Address correspondence to this author at the School of English Media Studies and Art History, University of Queensland, St Lucia., Brisbane, QLD 4072, Australia; Tel: 0061 (0) 7 33653201; Fax: 0061 (0) 733652799 ; E-mail: r.fitzgerald@uq.edu.au ways in which 'guilt' is ascribed and resisted. Indeed an awareness of the consequentially of such categorization of personal or projected guilt can be seen in the work participants do at times to resist categorisation such as in youth facilities (Osvaldsson, 2004), youth subcultures (Widdicombe \& Wooffitt, 1995), ethnicity and ethnic identity (Day, 1998; Leudar \& Nekvapil, 2000), age (Nikander, 2002), physical competence (Parry, 2004), marriage breakdown (Cuff, 1980), political, ethnic and religious affiliation (Leudar \& Nekvapil, 2000; Roth, 1998), shelter residency (Juhulia, 2004) and discriminatory views (Roth, 1998).

In this paper, build and extend (Austin \& Fitzgerald, 2007) this analysis of resistance to categorisation where that categorisation is of 'guilt'. In the first, the quasi institutional context of a research interview conducted in the style of a narrative therapy counseling interview where the interviewee attempts to distance herself from implicit accusations of being 'bad mother' and feeling guilty about it. In this case, we focus on the delicate category work she does that both reveals the possibility of a 'version' (Cuff, 1980) of herself as bad mother and how she resists that possible categorization. Baker (2004) has established a firm groundwork for MCA in the context of interviews. In the second, a group of friends discuss the extent to which a 'victim' and 'offender' are really 'guilty' in a case of rape, despite a criminal conviction being secured and the accused currently serving time in prison. Through the analysis we demonstrate how ascription and resistance to 'guilt' is grounded in accounts of activities interpreted through category attributes and individual action. These accounts are used to provide commonsense reasoning practices where individual actions are treated as recognizable and routine category bound actions of the invoked categories 'bad mother' and 'rapist'. It is this commonsense reasoning between the individual and categorial actions that serve as the focus of our analysis. 


\section{COMMON SENSE AND CATEGORIAL METHOD}

The methodological approach adopted in this paper is Membership Categorisation Analysis (MCA). MCA, first developed by Harvey Sacks, $(1974,1992)$ and developed by subsequent authors (McHoul \& Watson, 1984; Watson, 1997; Hester \& Eglin, 1997; Jayyussi, 2002; Housley \& Fitzgerald, 2002; Fitzgerald \& Housley, 2002; Fitzgerald \& Housley, 2006) examines the way members construct their interaction and display their knowledge of the world through the complex but methodical organisation of social categories, the mapping of predicates to these categories, and the grouping of these categories into devices. It is this process of commonsense categorisation that Sacks demonstrates through his example of a child's story 'The baby cried. The mommy picked it up' (Baker, 2004). The power of Sack's descriptive apparatus is illuminated by the analytic consideration of how we hear and make sense of the story as one in which a mummy picks up her baby in response to the baby crying. For Sacks, our understanding of this story is generated through recognising the social categories 'baby' and 'mommy' as related, or tied, to each other through the organisational device 'family'. Through this common sense recognition procedure a set of expectable attributes (or predicates) may be associated with the categories referenced (i.e., baby's cry, mothers comfort their children) and linked together within the organisational device 'family'. This constitutes the actions as not only expected but also directed at each other, i.e., this baby's crying is for its mother, and the mommy's action is because her baby is crying. Thus, the way we hear the story is that it is the mother of the baby who picks up the baby and she does so because her baby is crying, when in fact no such necessary connection is explicit in the two sentences. That is to say, we make sense of the story through applying our common sense knowledge about the way social categories act and interact (Sacks, 1992). Importantly, we apply this knowledge locally (Hester \& Eglin, 1997 ) as there is no essential or a priori connection between descriptions of social categories, their behaviour or their interaction. Rather, baby and mommy are seen to belong together in this instance but may belong to other organisational devices at other times depending on the local specifics of their relevance. Given that any one person can be legitimately understood in terms of several categories in several devices, the question guiding Sacks' analysis is how then members know which categories and what relations are relevant at this time. Sacks observed that two 'rules of application' are routinely at work in sense-making, describing them as the 'economy rule' and the 'consistency rule'. As Sacks' (Sacks, 1992) described, the economy rule refers to the practical process by which 'if a member uses a single category from any device then he/she can be recognised to be doing adequate reference to a person' and the consistency rule states that 'if a member of a given population has been categorised within a particular device then other members of that population can be categorised in terms of the same collec-

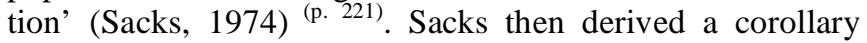
known as the 'hearers maxim' which states 'if two or more categories are used to categorise two or more members of some population and those categories can be heard as categories from the same collection then: hear them that way' (Sacks, 1974) ${ }^{(\text {p. 221) }}$. The rules of application therefore work as practical sense making registers, such that for example, once the category 'baby' is heard, 'mommy' is relevantly heard to be grouped in the same device as 'baby', the device 'family' groups these categories in routine common sense. Categories, then, are collected within occasioned organisational devices that form a major part of the commonsensical framework of members' methods and recognisable capacities of practical sense making.

Since Sack's initial outline the method has been developed in a number of ways (Sacks, 1992; Housley, W \& Fitzgerald, 2002). One of which is to reveal that categorisation procedures can be seen to establish a practical and occasioned moral order (Jayyussi, 2002) where actions are accounted for and/or rendered accountable though normative assessments in terms of the obligations and expectations of the moral order. For example, mothers should pick their crying babies up and may be held accountable to their actions vis-à-vis their crying babies. Individual action can then be accounted for within the reasoning provided by categorial ordering where building an account involves transforming individual actions (including non actions, and expected action) into categorial actions. Here then, we explore the way participants reasoning and category practice is used in the transformation of individual actions into categorial actions and vice versa with focus on the work these transformations are being put. In example one, Karen uses a categorial account to rebut a 'feeling' of guilt through category membership and thereby resist that categorisation.

\section{Karen: 'Just an Ordinary Mother'}

The work of 'being ordinary' can take many forms (Osvaldsson, 2004; Widdicombe \& Wooffitt, 1995; Day, 1998; Roth, 1998; Juhulia, 2004). In the data below ' $\mathrm{K}$ ' (Karen) is taking part in an interview (interviewer 'I') which is part of research about the experiences of mothers of children diagnosed with Attention Deficit Hyperactivity Disorder (ADHD). This research was conducted within ethics procedures of informed consent. In this example Karen works to resist membership of the category 'bad mother' through resistance to a feeling of "guilt" which is predicated to the category. She does this through, among other things, reformulating behaviours as ordinary within an alternate category system, and, reformulating category-predicate relations through individual and categorial reasoning.

\section{Extract 1: What is a bad mother?}

$31 \mathrm{I}: \quad(1.0)$ what is a bad mother

$32 \mathrm{~K}$ : (.5) well I yell and scream and probably hit your children and

33 chase them around the house with a wooden spoon (.5) probably being

34 a little bit over protective (.) i might do that in a way and don't even know I'm

35 doing it (.) that's probably being bad

$36 \mathrm{I}: \quad(1.0) \mathrm{i}$ wonder if you look on the things that you do as bad because

37 Jenna is not able to manage herself (.) $\mathrm{i}$ wonder if it would be bad if

38 she was a regular kid (.) i w wonder if that makes you feel guilty 
$39 \mathrm{~K}$ : i just feel ba:d because i'm aware of the inner child and we need

nurturing (.) then again they can be little rat bags (.) they can be

manipulative (.) you have to put up the barriers and raise the standard

and say wait a minute i don't have to put up with that

Having made the first definitive statement both of category predicates and category membership 'I yell and scream' Karen's predicates and membership are qualified through the modifier "probably hit and chase", then "probably overprotect" and "probably being bad". The actions being ascribed as a predicate of the category Bad Mother are resisted through a reciprocity organisation such that Karen displays knowledge of what a Bad Mother would do (and hence what she would be doing if she was one) and through this distances herself from those actions. The description also downgrades her identification with the category by caricaturing or parodying those actions. Mothers who "hit your children and chase them around the house with a wooden spoon" (extract 1, line 32). Here then, Karen invokes various predicates which she attributes, and assumes reciprocity, to the category 'bad mother' to show that she is not a member of that category, even if she occasionally does these actions, or is seen to do these actions by others. This draws upon a moral organisation that if a person knows she is being a bad mother then she would want to stop being one - the moral organisation of bad and good mother is not inherent in the action but in the recognition and interpretation of the action as documenting a category. Indeed, given the session is about being a 'bad mother', Karen's description acts to resist the omni-present (Sacks, 1992) ${ }^{24}$ category incumbency by the fact that she is aware of her actions which proves that she is not one. In a sense she is saying, 'If I were a member of the category 'bad mother', these are the things I would be doing and I would not be aware they were bad'. Moreover the description offered is a caricatured rendering of the category 'bad mother', reminiscent of a 'wicked stepmother' fairytale character. Again this serves to distance Karen from such membership as it makes light of the category by positioning it as the product of the fictional world rather than the real world. This caricatured category is then replaced with another version of the category - again qualified, "probably being a little bit over protective" (extract 1, line 33).

This new predicate of overprotection is in contrast to the previous predicates of hit and chase. Rather it is offered as a predicate of a 'too-caring' mother, an overprotective mother, and therefore a different category of 'bad' mother. This is akin to the 'I work too hard' response to the job interview question 'what are your faults?'. It presents a hearably positive action in a pseudo-negative way. In this case the fault of the overprotective mother is to care too much, which of course means that she is not 'really' a 'bad' mother, with possible predicates of shouting and chasing, but a mother who worries too much and acts on her child's behalf. Furthermore the predicate 'overprotectiveness' is qualified through 'probably' and 'little bit' and then weakened and downgraded further as somewhat involuntary and unmarked: "I might do that in a way and don't even know I'm doing it" (extract 1, lines $34 \& 35$ ). Thus, in the first utterance when asked to reflect upon what is a 'bad mother' Karen invokes various caricatured predicates before offering an alternative for her as indeed 'ordinary', indeed so normal and ordinary it does not even enter her awareness. In effect she claims she is not so much an overprotective mother (itself not such a bad thing) but a mother who is sometimes overprotective but is also unaware she is being so.

\section{Is Karen Guilty or Bad?}

Karen's initial strong statement of the predicate "yell and scream" and membership 'I', although now complicated and qualified, remains 'on the table' (as evidenced by further moves by both Karen and I). The interviewer's response to Karen presents formulations of prior talk as a series of wonderings posed as questions (extract 1, lines36-38): "I wonder if you look on the things that you do as bad because Jenna is not able to manager herself", "I wonder if it would be bad if she was a regular kid", "I wonder if that makes you feel guilty". Karen rejects all these possibilities a provides a reformulation. She resists the offered feeling of guilt by replacing it with feeling bad. Karen has resisted membership of one category of bad mother and constructed a different category with predicates of overprotectiveness. She maintains her membership of the downgraded category overprotective bad mother by resisting the counselor's offer of feeling guilt. Thus by constructing her actions in relation to the reoriented category of 'overprotective bad mother' that she now belongs to, and is therefore in control of, she is then able to reject further predicate work by the counselor when trying to attach the predicate of 'feeling guilt' to Karen. This category work is reinforced through various pronoun shifts in the process of moving from individual to categorial relevance. Firstly, Karen's own individual account of her feelings, awareness and knowledge is established: "I feel", "I'm aware", and these individual predicates are then incorporated into a general or universal "we" and "we need nurturing" (extract 1 , lines $39 \& 40$ ).

In building the category around her Karen then invokes the relational pair for the overprotective bad mother, that of child, "They are little rat bags and are manipulative" (extract 1 , lines $40 \& 41)$. In the context of this account "they" are hearably "children', or more specifically "they" could be the children of this context, that is, children with ADHD. Whoever "they" are, "they" are quite ordinarily manipulative ratbags at times. "They" do not have a claim to nurturing, rather "they" are to be protected against, barriers can be put up and they do not have to be "put up with" (extract 1, lines $40-42$ ). That is, in this categorial organisation when being 'ratbags', children are displaying predicates not of "we" but of "they". Their behaviours then invoke from "overprotective mothers" "putting up barriers" and "raising standards" (extract 1 , lines $41 \& 42$ ).

In the next categorial move, the behaviours of "putting up barriers" and "raising standards" are established as reasoned in the face of the ratbaggery "You have to ..." with "you" acting to establish this as ordinary, "what anyone would do'. Finally these categorial relevances are cycled back into an individual account of Karen's behaviour "I don't have to put up with that" (extract 1, line 42). Thus the actions of 'putting up barriers and not putting up with them' 
are reasoned through the categorial relationship of 'mother and child' within the device 'mothers of children with ADHD' whereby there is an oscillation between the individual and categorial actions as categorial reasoned responses. In normalising the child's behaviours she normalises her own response. Karen's behaviours can now be read within the moral categorial order of a normal sensible person not putting up with manipulative behaviour. The "yelling and screaming" of Karen's first utterance has now been formulated as a justifiable and normal action of "putting up barriers and not putting up with that" in face of "their" behaviour (extract 1, line 41). This formulation of the ordinariness of actions is also apparent in the next example where guilt is resisted through individual and category reasoning organised through categorial predicates and their relation to the reported actions of other.

\section{"That Fat Slag Toni... and She Led Im on as Well Like"}

In institutional settings the matter of someone's guilt or responsibility for their actions is a product of reasoning practices entered into between members institutionally charged with making a decision upon a person's actions and invoking further actions in respect to that decision. As suggested in the introduction however, whilst reasoning practices around deciding someone's guilt are seen as the business of some institutional talk, ascribing, reasoning and negotiating guilt are not confined to institutional talk. Rather the work of accusations, assumptions, imputations and defense are a routine part of social interaction where deciding negotiating, defending, arguing and judging actions that can occur in any context. The data is taken from a conversation between friends Jimmy, Shirl and Ruth. In the extracts below Jimmy initiates the topic of a recent local rape case and the culpability of the victim. Our interest here is in locally contingent categorial methods used by the participants in negotiating the degree of guilt or innocence of the parties being discussed. That this is overwhelmingly a matter of local in situ negotiation between the participants is of particular interest as the reasoning practices are organised through and underpinned through an oscillation between individual actions, categorial actions and category membership.

\section{Extract 2 (Jimmy, Shirl and Ruth)}

[30] J: =well look at D::av's Da:d (.) I don't know how much truth is in

$$
\text { that bout er= }
$$

S: $\quad$ =with that fat slag Toni=

R: $\quad=$ who's that?=

J: =you know-phhhhhh-yu know Jean Roberts-Phil Roberts' Mum

[her granddaughter] -

$$
\text { S: } \quad \text { [an she led] im on as well [like] }
$$

During a conversation in which a round of stories is told about offenders the group knows, Jimmy, at line 30 introduces a new story. Between line 30 and 35 the characters of the new story are presented and collected within device 'parties to a rape' organised through a standardised relational pair collected from "Dav's Dad" and "that fat slag Toni": where Toni as "that fat slag" is heard as female rather than male. Whilst the character of Dav's Dad remains a personal one, the reference to Toni as "that fat slag" renders her character as a categorial one. This initial personal/categorial move provides a categorially organised account for Dav's Dad's behaviour as he was "led on" by Toni, now categorised as a 'fat slag'. Thus, Shirl does not deny that Dav's Dad and Toni had sex; rather the context of the encounter is challenged through invoking a category membership for Toni and then relating an attribute of that category as explanation for Dav's Dad's action. In the next extract Jimmy then challenges Shirl's prior category work by attempting to transform the category 'fat slag' back to an individual identity based on what it is possible for Shirl to know about what happened.

\section{Extract 3}

[38] J:

$$
\begin{aligned}
& \text { you don't actua:lly know like do y::a } \\
& \text { Sh:irl? (.) There might-I--I think } \\
& \text { there's a lot more to it but I don't know } \\
& \text { [so I'm not gonna judge either ov um] }
\end{aligned}
$$

By questioning Shirl's account of Toni's actions, at line 38 , Jimmy attempts to undermine the reasoning between the category 'fat slag' and the predicated action of 'leading Dav's Dad on'. Stating that Shirl was not in a position to know what went on between Dav's Dad and Toni as she could not have been there to witness any 'leading on' undermines the invoked category membership, and hence Shirl's categorial account for what happened. Thus, although Toni may remain a member of the category 'fat slag' in Shirl's opinion, she does not give any description of Toni's actions (predicates) that would document her membership of the category. In response to this, Shirl attempts to reconcile that connection and give evidence for her initial categorisation.

\section{Extract 4}

[41] S:$$
\text { S: } \quad \text { [I used to knock] around with er [for }
$$
years]

R: $\quad[\mathrm{I}:: \mathrm{s}]$ that

Julie Roberts' daughter?

$$
\begin{array}{ll}
\text { J: } & \text { yer } \\
\text { S: } & \text { I was hangin round with her at the time }
\end{array}
$$
when she got raped like=

Through invoking personal knowledge of Toni at lines 41 and 45, "at the time when she got raped", Shirl attempts to recover her categorial account of Toni as a 'fat slag', and thus the sort of person who would 'lead on' Dav's Dad. Although not claiming that she was present when the events took place, she claims a position from which to have observed Toni and hence know the kind of person Toni is. From this observation she is able to argue legitimate, or objective, categorisations from which to reconnect her category of 'fat slag' and the predicate of 'leading on' for this event. However, this move by Shirl is again challenged by Jimmy who responds by attempting to downplay the relevance of Shirl's personal knowledge and introduce his own personal knowledge of Toni. 


\section{Extract 5}

[51] J: =but whatever you say bout er like I jus can't se-cause she's not a

bad lookin girl like I can't [see]

S: $\quad$ [I wouldn't] say that (.) Not when she

was younger she was[fat an spotty]

J: [well] she's not (.) Put it this way

I can't see a girl that age which I mean she's not-t(.) She's not a

miss world but she's not what yu'd call ugly is she right I can't see

why a girl that age would want to go with somebody like Dav's Dad?

R: but it happens all the time Jimmy

$\mathrm{J}: \quad$ it does happen all the [time]

R: [all] the [time]

S: [what] bout Donna?

J: $\quad$ yer fur money-possibly that might av been what happened

yu don't know or possibly its ha whawhat-the only// lead=

$\mathrm{R}$ : could be for attention=

At line 51 Jimmy attempts to undermine the category description and related predicate of Toni by invoking a new predicate for the category 'fat slag', as 'ugly' or 'bad looking'. i.e., the corollary of Toni being "not a bad lookin girl" is that she does not need to lead men on and, and so is not a member of the category 'fat slag'. In a similar, but reversed, move to Shirl, Jimmy also invokes personal observation of Toni as evidence of her not having to lead men on (a predicate of the category 'fat slag'). Thus, the individual and categorial work by Jimmy is also based on his personal observation of Toni where what he sees does not fit with the category description, the associated actions and thus the implied guilt. However at line 53 Shirl interrupts and produces her own personal observation and assessment of Toni's attractiveness. Shirl shifts the time frame back to when she knew her, at the time of the rape, to describe her as "fat and spotty". So, irrespective how Jimmy sees Toni now, Shirl's time frame for observing Toni as "fat and spotty" protects her category work and her assessment of the context that Toni led Dav's Dad on.

At line 56 Jimmy then begins to set up a categorial device by which to judge Toni's attractiveness and hence her category membership. Jimmy creates a categorially ordered continuum onto which the others are invited through a preference structure, "she's not what yu'd call ugly is she right", to evaluate the position Toni occupies. With the assessment of Toni as "not a bad lookin girl" comes a reference to her age, established as sixteen previously at line 50 . These attributes predicated to Toni serve to further challenge Shirl's categorisation of Toni as 'fat slag'. For Jimmy, the category 'young girl who is not ugly' would not want to, or need to, have sex with an older man, and so would not need to lead anyone on. At line 58 Jimmy then sets up a categorially ordered puzzle where for someone 'like' Toni to willingly have sex with someone "like Dav's Dad" would require more explanation (a dispreferred organisation), whereas, in reverse, someone "like Dav's Dad" is the type of category to be seen as wanting to have sex with someone 'like' Toni if she is young and good looking.

However at line 59 Ruth neutralises the category explanation through rendering the morally ordered category scenario as routine, that the disjuncture is a routine one, and so unremarkable or non-puzzling. The level of abstraction invoked through the initial continuum established by Jimmy is now matched by Shirl with an invitation to agree that it does happen, with "Donna" given as an example as to why a good looking girl might willingly have sex with an older man. At this point Jimmy offers one further layer of evidence as to why the attributed actions of Toni might not be correct.

\section{Extract 6}

[66] J: =the only thing right that made me think right Ruth, I-he was

[81] J: err me mum used to take all ov uz (.) but

err (.2) the thing that

[99] J: right so e told me thats why e-went guilty

[100] but like I don't care (.) IF some girl ad said I'd rape-ter an I-adden't

[101] (.) I don't care like whether she's gonna go thru loads of stress

[102] in the box cause the girls l::ying like.

At line 66-67 Jimmy offers that he spoke to Dav's Dad whilst in Risley (a remand prison in the UK) about the event and they talked about why he was pleading guilty. Thus, whilst Shirl claims she knows Toni and so is in a position to offer an account of Toni's actions, Jimmy now lays claim to knowledge about the event through a conversation he and Dav's Dad had about why he pleaded guilty. Jimmy relates that even though Dav's Dad was charged with rape and pleaded guilty to the offence, he said he only pleaded guilty for other reasons such that it would save the victim from further stress. However, after relating Dav's Dad's reasons for pleading guilty Jimmy then transforms this into a category organised disjuncture by constructing a scenario around the hypothetical situation where if faced with a similar choice he would not plead guilty. The reasoning is again achieved through categorial relationship where someone like him (category 'male') faced with accusations of rape would not let her (category 'young good looking girl') get away with it. 
Here then degrees of guilt are negotiated through a relationship between individual actions seen as categorial actions and category predicates related to individual actions. Furthermore, this shift between person and categorial reference throughout the discussion depending on what particular point is being discussed at any one time highlights the local management of the flow of the interaction as the parties present and argue their case to Ruth (see also the discussion by Fitzgerald, Housley and Butler [25]).

\section{SUMMARY}

Our discussion has focused on the way guilt is negotiated in two interactions. In the first the guilt was in relation to one of the participants whilst in the second example guilt was being ascribed to absent parties. The analysis highlighted the interrelationship between an individuals' action as part of reasoning practice for attributing category membership, where the legitimation to offer category descriptions rests on personal non-category knowledge. In using data from quasi and non formal situations we have attempted to show how the work of reasoning guilt is a routine practice not confined to more formal contexts. Rather the reasoning practices engaged above display similar reasoning practices to other more formal situations such as courtrooms. Indeed the sorts of reasoning practices around the process of deciding what counts as evidence ('you were not there') or resisting a loaded category 'bad mother' - as routine part of formal institutional contexts - are here used in the quasi institutional context of the narrative therapy come research interview and the informal context of friends in conversations. This then points to 'guilt' as overwhelmingly a member's phenomenon negotiated and situated in the everyday interactional topics and contexts. Furthermore, this analysis demonstrates the facility of MCA in understanding the delicacy and artfulness of such consequential negotiations.

The above discussion also suggests a connection with recent discussions around the analysis of mental states and cognition in various discourse approaches including MCA, Ethnomethodology (EM) and Discursive Psychology (Te Molder \& Potter, 2005; Housley, W., \& Fitzgerald, 2008; Housley, W., Fitzgerald, 2008; Edwards et al., 2008; Potter, 2006). In the analytic program of MCA/EM states of mind are not available except through displays and accounts of mental states in interaction (Lynch \& Bogen, 2005; Lynch, 2006). Thus, MCA/EM is not interested so much in speculating upon mental states but rather in how mental or cognitive states of mind are displayed, utilized, attributed and put to work within interactional tasks. Above we highlight the way Karen resisted the feeling of guilt attributed to the category of bad mother by instead offering that she felt bad. That is to say, her resistance to the category 'bad mother' was clearly organised through resisting the emotional action offered. This points to the analytically interesting idea that membership categories may include cognitive or mental states as part of their attributes, and that these cognitive predicates are assumed to be active by dint of membership of the category. For example, with the category 'parent', love for one's child is assumed and becomes news when this is not the case, or that passion is assumed as part of the category 'artist' who may lose their passion/interest and so explain their lack of artistic work. This suggests an interesting avenue for MCA analysis as it highlights the possibility of exploring the interactional use, deployment, ascription and resistance of categorially ordered cognition.

\section{REFERENCES}

Atkinson, J. M., \& Heritage, J. (Eds). (1984). Structures of Social Action: Studies in Conversation Analysis (pp. ix-xvi). Cambridge: Cambridge University Press.

Austin, H., \& Fitzgerald, R. (2007). Resisting categorisation: An ordinary mother. Australian Review of Applied Linguistics, 30, (3), 36.136.13 .

Baker, C. (2004). Membership Categorisation in Interview Accounts. In Silverman D. (Ed.), Qualitative Research: Theory, Method and Practice London: Sage, pp162-176.

Cuff, E.C. (1980). Problems of Versions in Everyday Situations, 1993 International Institute for Ethnomethodology and Conversation Analysis and University Press of America, Washington D.C., previously published as Some Issues in Studying the Problem of Versions in Everyday Life, Occasional Paper, Department of Sociology, University of Manchester.

Day, D. (1998). Being ascribed and resisting, membership of an ethnic group. In Antaki C. \& Widdicombe S. (Eds.), Identities in Talk. London: Sage. pp.151-170.

Drew, P. (1992). Contested Evidence in courtroom cross-examination: the case of a rape trial. In Drew $\mathrm{P}$ and Heritage J. (Eds.). Talk at Work. Interaction in Institutional Settings. Cambridge: Cambridge University Press. pp 470-520.

Drew, P. \& Atkinson, M. (1979). Order in Court; the organisation of Verbal Interaction in Judicial Settings. London: Macmillan.

Edwards, D., Hepburn, A., Potter., J. (2008). Psychology, Sociology, and Interaction: Disciplinary Allegiance or Analytic Quality. Qualitative Research. 8, (3), (in press).

Fitzgerald, R., \& Housley, W. (2006). Categorisation, Accounts and Motives. 'Letters-to-the-editor' and Devolution in Wales. In J Wilson., \& Stapleton K. (Eds.), Devolution and Identity Aldershot: Ashgatepp. 111-126.

Fitzgerald, R. \& Housley, W. (2002). Identity, Categorisation and Sequential Organisation: The Sequential and Categorial Flow of Identity in a Radio Phone-in. Discourse and Society, 13, 579-602.

Hester, S. (2008). Describing 'Deviance' in Schools: Recognisably Educational Psychological Problems. In Antaki C., \& Widdicombe S. (Eds.), Identities in Talk London: Sage. pp. 133-150.

Hester, S., \& Eglin, P. (Eds). (1997). Culture in Action, Studies in Membership Categorization Analysis. Lanham, MD: University Press of America and International Institute for Ethnomethodology and Conversation Analysis.

Housley, W., Fitzgerald, R. (2008). Beyond the Discursive: The case of social organisation. A reply to Edwards, Hepburn and Potter. Qualitative Research. 8, (3), (in press)

Housley, W. \& Fitzgerald, R. (2002). The Reconsidered Model of Membership Categorisation. Qualitative Research, 2, 59-83.

Housley, W., \& Fitzgerald, R. (2008). Motives and Social Organisation: Sociological Amnesia, Psychological Description and the Analysis of Accounts, Qualitative Research. 8, (2), 237-256.

Jayyussi, L. (1984). Categorisation and The Moral Order. London: Routledge and Kegan Paul.

Juhulia, K. (2004). Talking back to stigmatized identities: Negotiation of culturally dominant categorization in interviews with shelter residents. Qualitative Social Work. 13, (3), 259-275.

Leudar, I., \& Nekvapil, J. (2000). Presentations of Romanies in the Czech media: On category work in television debates. Discourse and Society, 11, 487-513.

Lynch, M. (2006). Cognitive activities without cognition? Ethnomethodological investigations of selected 'cognitive' topics. Discourse Studies, 8, (1), 95-104.

Lynch, M., \& Bogen, D. (2005). 'My Memory Has Been Shredded': A Noncognitivist Investigation of 'Mental' Phenomena'. In Te Molder H., \& Potter J. (Eds.), Conversation and Cognition, Discourse, Mind and Social Interaction. Cambridge: Cambridge University Press. pp. 226-240.

McHoul, A., \& Watson, R. (1984). Two axes for the analysis of 'commonsense' and 'formal' geographical knowledge and classroom talk. British Journal of the Sociology of Education, 5, 281-302. 
Nikander, P. (2002). Age in Action: Membership Work and Stage of Life Categories in Talk. Helsinki, Finnish Academy of Science and Letters.

Osvaldsson, K. (2004). I don't have no damn cultures. Doing normality in a deviant setting. Qualitative Research in Psychology, 1, 239-264.

Parry, R. (2004). The interactional management of patients' physical incompetence: A conversation analytic study of physiotherapy interactions. Sociology of Health and Illness, 26, (7), 976-1007.

Pollner, M. (1987). Mundane Reason. Reality in everyday sociological discourse. Cambridge University Press. Cambridge.

Potter, J. (2006). Cognition and conversation. Discourse Studies, 8, (1), 131140.

Roth, A. (1998). Who makes the news? Descriptions of television news interviewees' public personae. Media Culture and Society, 20, 79107.

Sacks, H. (1974). On the analyzability of stories by children. In Turner R. (Ed.), Ethnomethodology: Selected Readings. Harmondsworth: Penguin Books. pp. 216-232.

Sacks, H. (1992). Lectures on conversation Vol I. and II. Jefferson G. (Ed.), Oxford: Basil Blackwell.

Te Molder, H. Potter, J. (Eds). (2005). Conversation and Cognition. Cambridge, Cambridge University Press.

Watson, R. (1997). Some General reflections of 'categorisation' and 'sequence' in the analysis of conversation. In Hester S. \& Eglin P. Eds. Culture in Action, Studies in Membership Categorisation Analysis. Lanham, MD: University Press of America and International Institute for Ethnomethodology and Conversation. pp. 49-76
Widdicombe, S., \& Wooffitt, R. (1995). The Language of Youth Subcultures: Social Identity in Action. Hemel Hempstead: Harvester Wheatsheaf.

Transcription notation is adapted from Gail Jefferson as detailed in Atkinson and Heritage (Atkinson \& Heritage, 1984). These conventions denote lapses in time, overlapping talk, pace and in some instances pitch, pronunciation and stress. We have only included those symbols used in the transcriptions.

Square brackets indicate overlapping talk.

[41] S: [I used to knock] around with er [for years]

[42] R: [I::s] that

Numbers in Parentheses: e.g. (1.0) denotes the approximate duration pauses or gaps between utterances in seconds or tenths of seconds.

Point in Parentheses: (.) indicates a 'micro - pause' of less than two tenths of a second.

Letters, words or activities in double parentheses: ((cough)) sounds, words or activities that are distinct or difficult to locate to a particular interlocutor (s).

Full Colons: ( : ) denote an extension in the vowel or consonant sound in the utterance of a word.

Emphasis: (CAPITALS) indicates specific emphasis and change in volume. Underlined word: ( as we said) indicates pitch change.

Equals signs: $=$ identifies a 'latching' between utterances, whereby which utterances follow each other rapidly after a preceding utterance.

Italics: (anything that moves) delivered at faster pace

(C) Fitzgerald and Austin; Licensee Bentham Open.

This is an open access article distributed under the terms of the Creative Commons Attribution License (http://creativecommons.org/licenses/by/2.5/), which permits unrestrictive use, distribution, and reproduction in any medium, provided the original work is properly cited. 